\title{
THE INFLUENCE OF BULK AND SONIC PLACEMENT TECHNIQUES ON MICROLEAKAGE OF CLASS II CAVITIES RESTORED WITH DIFFERENT RESIN COMPOSITES
}

\author{
Rabab Mehesen*, Laila E Amin ** and Marmar Montaser*
}

\begin{abstract}
Aim: To evaluate the microleakage of three different restorative composite resins through gingival margins of proximal boxes by dye and bacterial penetration techniques.

Materials and Methods: Class II slot cavities were prepared for sixty sound human premolar teeth. The teeth were divided into 3 main equal groups of 20 teeth each. Group I cavities were restored with Filtek Z250XT and considered as control ones while those of group II and III were restored with Sonic-filled Filtek Z250XT and Tetric EvoCeram Bulk Fill, respectively. At first, all teeth were undergone thermal cycling and then each group was sub-divided into 2 subgroups of 10 teeth each; according to the microleakage technique used.
\end{abstract}

Results: Monte-Carlo Statistical test showed that the three tested groups had no significant differences among them for the two techniques

Conclusions: Sonic-fill technique had the least marginal leakage over the other techniques confirmed by both dye and bacterial leakage testing.

KEY WORDS: Sonic-fill, Bulk-fill, Dye microleakage, Bacterial penetration.

\section{INTRODUCTION}

The resin-based direct composite restorations have become a commonly used technique in dental field. ${ }^{1}$ Although composite restorative materials have improved during the last several years, there remain the problems regarding polymerization shrinkage and placement technique. ${ }^{2}$ During the process of polymerization, monomers convert into a dense cross-linked polymer with a decrease in the overall free volume within the monomers creating volumetric shrinkage. This shrinkage develops stresses that transferred to the tooth-restoration interface. ${ }^{3}$ Clinically, the process of de-bonding occurs resulting in subsequent microleakage permitting bacterial passage, fluids, and toxins leading to postoperative sensitivity, marginal gap formation and recurrent

* Lecturer of Operative Dentistry, Faculty of Dentistry, Mansoura University, Egypt.

** Assistant Professor of Oral Biology, Faculty of Dentistry, Mansoura University; Assistant Professor of Oral Biology, Faculty of Dentistry, Horus University, Egypt. 
caries. ${ }^{4,5}$ Despite the incremental build-up of composite resin is regarded as a gold-standard technique over years, it may lead to formation of voids among the increments, failure of bond and the wasting of time during this procedure. ${ }^{6}$

Bulk-fill composite resins restorative materials with higher polymerization depth, lower polymerization shrinkage stresses and decreased cuspal deflection rates become available. This technique applied into the teeth cavities in layers of about $4 \mathrm{~mm}$ thickness, ${ }^{7}$ and this is due to being formulated with high color translucency and innovative of polymerization initiation system increases the depth of cure. ${ }^{8}$ Also, ultrasonic vibration technique is another method as a flowable resin composite by decreasing the primary viscosity to allow adequate wetting and adaptation of the closely filled resin composite onto the dental procedures. ${ }^{9}$ Sonic driven resin composite application device technology uses the thixotropic properties of composites by changing only the viscosity, without changing the chemical or mechanical characteristics of the material. The second generation of sonic system devices contain the advantage of flowable composite with a universal composite. This smart device give the composite material good adaptation, superior reduction of voids, precise application, and layer thickness control. ${ }^{10,11}$

In vitro investigations are used to offer data about the marginal and inner adaptation of the filling materials. The dyes are widely used, but this test is not accurate for evaluating leakage involving bacteria. Highly sensitive methods are used to assess the early marginal microleakage as scanning electron microscopy (SEM), and bacterial penetration. ${ }^{12}$ So, it is better to use bacteria in assessing microleakage. The objective of current work was to evaluate the role of 3 variable restoring methods on microleakage of different composite resins restorative systems by using two testing techniques which were die and bacterial penetration. Our null hypothesis expected no statistically significant differences between them

\section{MATERIALS AND METHODS}

\section{Specimens' preparation and grouping}

Sixty sound, human upper and lower premolars have been collected from the Out patients' Clinic, Faculty of Dentistry, Mansoura University. All the selected premolars were recently extracted for orthodontic treatment and obtained after taking the patients' consent. They were cleaned with an ultrasonic scaler (XH-E412 ultrasonic cleaner, xinghua Ltd, china) in order to remove any soft tissue remnants, then disinfected by storing in $0.5 \%$ chloramine- $\mathrm{T}$ solution at room temperature for 48 hours. ${ }^{13}$ Selected teeth have been tested under $30 \mathrm{x}$ magnification using a binocular stereomicroscope (SZ-PT, Olympus, Tokyo, Japan) to confirm that the teeth were free from cracks. The selected teeth were kept in physiologic saline consists of $0.05 \%$ sodium acid at $37^{\circ} \mathrm{C}$ to avoid bacterial or fungal accumulation. ${ }^{14,15}$

Standardized class II slot cavities were prepared for all premolars, the cavity dimensions were $4 \mathrm{~mm}$ length from the occlusal surface to the gingival floor, $3 \mathrm{~mm}$ bucco-lingual width, and $2 \mathrm{~mm}$ axial depth. Then they were classified randomly into 3 equal groups of 20 teeth each; according to the restorative material used. Cavities of group I were served as control and restored with conventional composite restoration (FiltekZ250XT and Single Bond, 3MESPE Konstanz, Germany). While cavities of group II were restored with sonic-filled composite restoration (FiltekZ250XT and Single Bond, 3MESPE Konstanz, Germany) and those of group III were filed with bulk-filled composite restoration (Tetric EvoCeram Bulk Fill and ExciTE-F, Ivoclar vivadent, AG, Schaan, Liechtenstein). After restoration, each group was subdivided into to 2 subgroups of ten teeth each; for the two microleakgae tests. Ten teeth were subjected to the dye penetration 
microleakage testing and the other ten teeth for bacterial penetration microleakage testing.

\section{Specimens' restoration}

Whole restorative systems have been directed by manufacturers' instructions. A Tofflemire metal matrix with installed metallic band was contoured and positioned to surround the teeth and kept definitely at the proximal sides of the teeth during the restorative procedures. Etch-and-rinse bonding systems were selected for all resin based composites and used in the study to reduce future variability in the results. Each resin based composite system was used with its corresponding adhesive system following the manufacturers' instructions. The polymerization light was applied from the occlusal surfaces.

Sonic driven composite resin application device (Compothixo, Kerr Corporation) used to restore group II cavities is battery-operated and hand-held instrument (Fig. 1). When the device is turned on, the unit begins to vibrate at $140 \mathrm{~Hz}+/-20 \mathrm{~Hz}$. The instrument is prepared for $10 \mathrm{~min}$ discontinuous application. The device contains a handle and four tips in the form of pointed one, spatula tip, plugger tip and, semi-sphere tip. The instrument is motivated by means of the button on the handle in a technique like a basic instrument for composites. All groups were submitted to thermal cycling protocol by

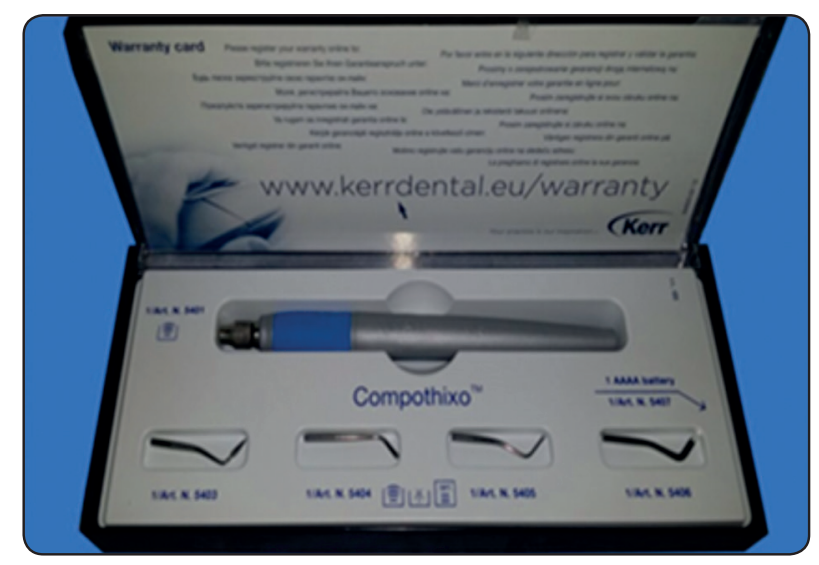

Fig. (1) Sonic-driven resin composite application device immersion alternately in water baths at $5 \pm 2{ }^{\circ} \mathrm{C}$ and $55 \pm 2^{\circ} \mathrm{C}$ for 2000 cycles, with a dwell time of 20 seconds in each bath and a transfer time of 5 seconds (SD Mechatronik thermocycler THE-1100, Germany).

\section{Evaluation of microleakage}

\section{a) Dye penetration microleakage testing}

The apices of the teeth were plugged by dental wax and the whole surfaces were covered with three coats of nail polish except restoration area and $1 \mathrm{~mm}$ rim of tooth structure around restoration. Then the specimens were immersed in $2 \%$ basic fuchsin coloring dye for 24 h. ${ }^{16}$ After immersion, the coating was removed from each specimen by scraping, washed thoroughly with running water and dried. Then, all the specimens were sectioned in mesio-distal direction to produce two halves. The sectioned surfaces were examined at cervical margin by a binocular stereomicroscope (SZ-PT, Olympus, Tokyo, Japan) at 40X magnification and scored according to the following scale:

0 - No dye penetration

1- Superficial dye penetration before ADJ (restricted to enamel of gingival wall)

2- Dye penetration beyond ADJ (limited to $2 / 3 \mathrm{rds}$ of gingival wall)

3- Dye penetration along gingival wall

\section{b) Bacterial penetration microleakage testing}

The teeth kept in a broth culture of $1.56 \times 10^{8}$ $\mathrm{CFU} / \mathrm{ml}$ (McFarlane standard) of Streptococcus mutans (clinical oral isolate) at $37^{\circ} \mathrm{C}$ for 10 days, permitting penetration of bacteria into the margins of prepared cavity. The broth culture was changed twice per week. After incubation, the nail polish was detached, and the teeth were fixed in a $10 \%$ neutrally buffered formal saline solution for $48 \mathrm{~h}$. all samples were decalcified in 5\% nitric acid and then washed carefully in running water for $18 \mathrm{~h}$, 
dehydrated and inserted in paraffin. Serial sections of $7 \mu \mathrm{m}$ thick were cut from each samples by a microtome. The bacterial staining processed via the Gram Color modified method. ${ }^{17}$ The samples stained with Brown\& Brenn bacteria detecting stain. The bacterial infiltration was assessed under light microscope at the magnification of 400X at General Pathology Department, Faculty of Medicine, Mansoura University, and they were classified on the subsequent scale:

0 - No stained bacteria.

1 - Positive staining of bacteria in walls and floor of prepared cavity

2 - Positive bacterial staining within the cut dentin tubules.

\section{Statistical Analysis:}

All collected data was subjected to statistical evaluation using Social Science software computer program version 23 (SPSS, Inc., Chicago, IL, USA). Data were presented in frequency (Numberpercent). The comparison of obtained statistics was achieved by Monte-Carlo test. Spearman's rho correlation coefficient test was used for correlating different parameters and $\mathrm{P}$ value less than 0.05 was considered statistically significant.

TABLE (1) Statistical results of the three tested groups using dye penetration microleakage testing.

\begin{tabular}{|c|c|c|c|c|c|}
\hline & Group 1 & Group 2 & Group 3 & $\mathrm{P}$ \\
\hline $\overrightarrow{\underline{\mathscr{E}}}$ & $\mathbf{0}$ & $0(.0 \%)$ & $2(20.0 \%)$ & $0(.0 \%)$ & \multirow[t]{4}{*}{0.4} \\
\hline đ & 1 & $1(10.0 \%)$ & $2(20.0 \%)$ & $0(.0 \%)$ & \\
\hline 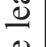 & 2 & $5(50.0 \%)$ & $4(40.0 \%)$ & $6(60.0 \%)$ & \\
\hline E & 3 & $4(40.0 \%)$ & $2(20.0 \%)$ & $4(40.0 \%)$ & \\
\hline
\end{tabular}
using dye penetration microleakage testing.
Fig. (2) Dye penetration microleakage of three tested groups

\section{RESULTS}

\section{a) Dye penetration microleakage testing.}

The scores of the three groups were compared and analyzed as displayed in table 1 and figure 2 . The groups presented mostly dye leakage in scores 2 , and 3 and statistically there is no significant differences among them. The stereomicroscopic images of different scores of all the tested groups are shown in figure 3.

\section{b) Bacterial penetration microleakage testing.}

The scores of the three groups were compared and analyzed as shown in table 2 and figure 4 . Also, the three tested groups shown no significant differences among them. All the groups showed mostly score 0 in bacterial penetration. The stereomicroscopic images of different scores of all the tested groups are shown in figure 5.

\section{c) Correlation between dye and bacterial penetra- tions.}

Spearman's rho correlation coefficient test was used correlating different parameters showing positive correlation between the results of both microleakage testing techniques (Table 3).

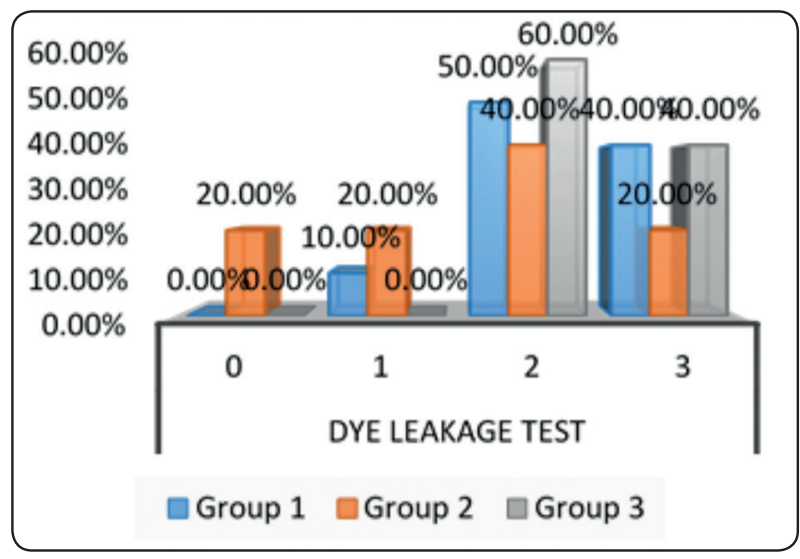




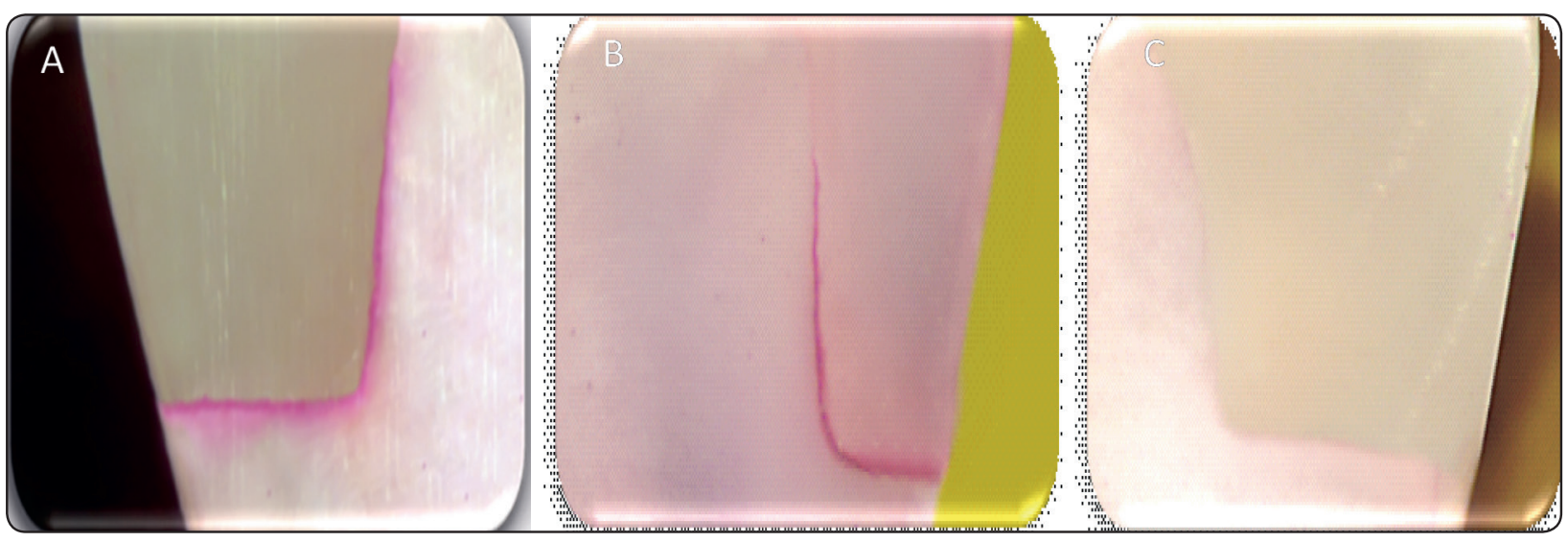

Fig. (3) Stereomicroscopic image: (A) Tetric Evoceram Bulk fill microleakage scores with score 3 showing dye penetration at axial wall of proximal box. (B) Filtek Z250 XT with conventional method of application showing score with dye penetration at axial wall of proximal box. (C) Filtek Z250 XT with application of sonic-driven device with score 0 showing no dye penetration.

TABLE (2) Statistical results of the three tested groups using bacterial penetration microleakage testing.

\begin{tabular}{|c|c|c|c|c|c|}
\hline & & Group 1 & Group 2 & Group 3 & $\mathrm{P}$ \\
\hline 苞 & 0 & $6(60.0 \%)$ & $8(80.0 \%)$ & $6(60.0 \%)$ & \\
\hline 离 & 1 & $2(20.0 \%)$ & $2(20.0 \%)$ & $2(20.0 \%)$ & 0.7 \\
\hline $\bar{E}$ & 2 & $2(20.0 \%)$ & $0(.0 \%)$ & $2(20.0 \%)$ & \\
\hline
\end{tabular}

TABLE (3) Spearman's rho correlation coefficient test of the two microleakage tests.

\begin{tabular}{|l|c|c|}
\hline & $\mathrm{r}$ & $\mathrm{P}$ \\
\hline Dye leakage \& Bacterial penetration test & $\mathbf{. 8 7 5}$ & $<\mathbf{0 . 0 0 1 *}$ \\
\hline
\end{tabular}

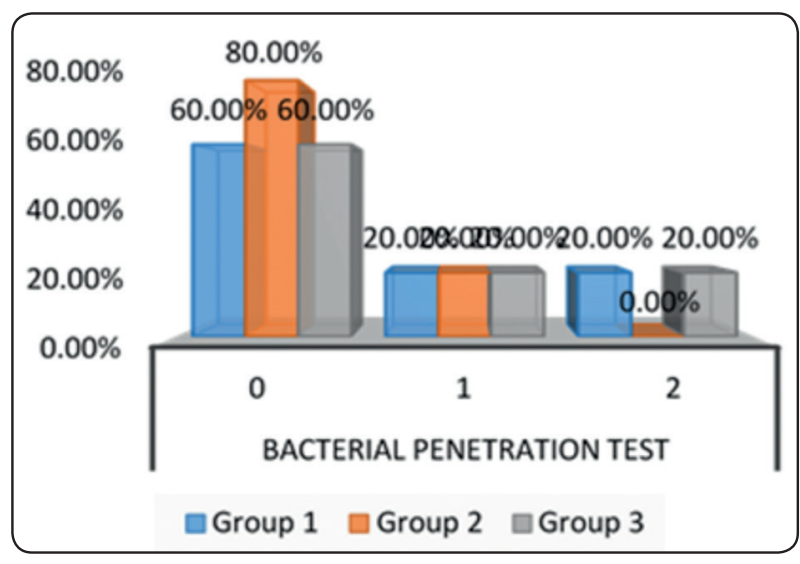

Fig. (4) Bacterial penetration leakage of three tested groups using bacterial penetration microleakage testing.

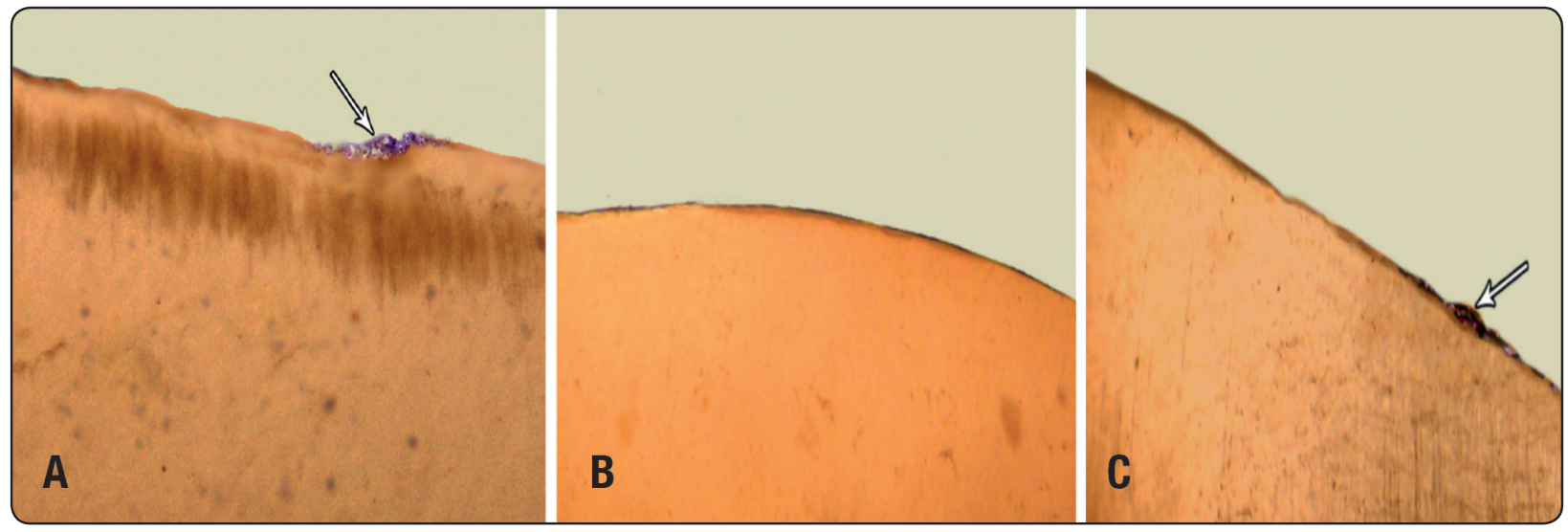

Fig. (5) (A) Tetric EvoCeram Bulk Fill with bacteria were detected in the cavity floor and penetrate dentinal tubules. (B) Filtek Z250 XT with application of sonic-driven resin composite application device bacteria were not detected in the cavity floor. (C) Filtek Z250 XT with conventional method of application bacteria were observed in the cavity floor (modified Brown and Brenn $\times 400$ ). 


\section{DISCUSSION}

Composite success story is still continuing by improvement of physical, mechanical, aesthetic and handling properties of both adhesives and composites. Despite these great improvements, composite restorations still have its usual polymerization shrinkage shortcoming. ${ }^{18}$ the adhesive between the tooth and the filling material, leads to failure of the bond and marginal penetration. ${ }^{19}$ Polymerization shrinkage depends on multiple factors; the C-factor, composites composition and properties..$^{20}$ It was established that high C-factor leads to more shrinkage stresses, and Class II cavities yield high C-Factor. ${ }^{21}$ Also, stresses produced along the tooth-restoration interface from repetitive temperature changes in the oral environment result in microleakage. Thermocycling is frequently working to initiate stresses in the oral cavity during lab investigations. ${ }^{22}$

Microleakage occurs by passage of fluids, bacteria, molecules or ions along tooth/restoration interface. ${ }^{23}$ This leakage sites lead to post-operative sensitivity and recurrent caries. ${ }^{24}$ These problems motivated the researchers to discover justifications to improve the technique to be more easy and faster. Sonic-fill method of restoration depend on an instrument which packs and adapts the resin by vibration in order to reduce the resin viscosity to be more easily flow and adapt to the cavity walls. Therefore, a high viscous restorative material can be used like a flowable composite, without high polymerization shrinkage and poor mechanical properties disadvantage. ${ }^{9}$ Bulk-fills developed to be cured in one $4-5 \mathrm{~mm}$ thick increment to avoid long time during layering process and air bubbles between increments..$^{25}$

The reported studies on microleakage can offer specific data and comparison of various novel restorative materials ${ }^{26}$ and clinical evaluations are time-consuming and expensive. ${ }^{27}$ Several techniques as bacterial, chemical or radioactive tracer molecules infiltration were used.$^{28}$ However, several means have been used to identify microleakage, there is no gold standard method. Dye penetration has been considered as an easy method since the dye penetrates successfully into the flaws and crevices of the test object, but it is influenced by the observer's ability to evaluate the infiltration. ${ }^{29}$ The dye penetration test is regarded a sensitive method to determine microleakage, as the particles of dye are smaller $(0.12 \mu \mathrm{m})$ than the size of bacteria $(0.5$ $1 \mu \mathrm{m})$ and diameter of dentinal tubules $(1-4 \mu \mathrm{m}){ }^{30}$

In the current study, the bacterial penetration test was used to support dye penetration results due to its advantage of its clinical relevancy. ${ }^{31}$ The $S$. mutans species was chosen as normally present in dental plaque and related to dental caries. ${ }^{32}$ These bacteria are $0.5-1 \mu \mathrm{m}$, which permits fast and easy infiltration into the dentin tubules through micro-gaps. The Gram and Brown-Brenn staining techniques were used to recognize the bacteria on the dentin walls and in the tubules. There are very few studies investigated bacterial microleakage. ${ }^{33}$

This study compared and evaluated among conventional layering, bulking single layer and ultrasonic flowing restoration techniques through microleakage testing at gingival margin. The margins examined by dye as usual in many studies, and by bacteria for more precise results. Then, the obtained resul ts were confirmed by positive correlation between two testing techniques. The outcomes of microleakage test revealed that there was no significant differences among three tested groups and sonic-fill showed lesser leakage patterns. Bacterial penetration were noticed in the wall and floor of some cavities, and detected inside the cut dentinal tubules. Iovan $G$ reported that condensation of composite resins can be faster when using vibrating instruments, and adaptation to the cavity walls is comparable to that obtained by traditional techniques. ${ }^{9}$

Also, microleakage was investigated by Eunice et al., who reported that the sonic system has no 
outcome regarding microleakage,,$^{34}$ and by Poggio et al., showed that sonic-fill composites can reduce microleakage values when compared with other groups tested microleakage. ${ }^{35}$ Although theestimated advantages of the ultrasonic packing techniques with highly-filled resin composite materials, however ultrasonic packing was not significantly beneficial over manual packing technique, owing to the incidence of polymerization shrinkage with nearly the same degree with all tested materials. ${ }^{36}$ Hassan et al., stated that ultrasonic packing technique outcomes is better but not statistically significant different adaptation values compared to application without ultrasonic of condensable composites, ${ }^{37}$ and another study found that Sonic Fill did not differ concerning results of adaptation. ${ }^{34}$ Schmidlin et al., described that ultrasonic energy significantly decrease the marginal gap..$^{38}$ Orlowski et al., explained that the most favorable gap results were attained by applying the Bulk-fill material with activating sonic handpiece. ${ }^{39}$

Bulk-fill resin based composites were related to lesser stress levels, regardless of the material type ${ }^{40}$ but they did not eliminate it to the extent that they prevent its harmful effect on stability and seal at marginal interfaces. Higher translucency and light transmission properties of bulk-fill resin were enhanced, and modified by adding prepolymer shrinkage stress relievers, polymerization modulators chemically embedded in the center of polymerizable resin backbone, high-molecular weight base monomer to optimize flexibility and network structure and highly light-reactive photoinitiator system, ${ }^{25}$ benzoyl germanium (Ivocerin) to enable rapid polymerization and greater depth of cure. ${ }^{41}$ There were no significant differences between groups 1 and 3 , and this came in agreement with Behery et al. compared the gingival microleakage of class II cavities restored with bulkfill composites to incrementally restored with a conventional composite. They found that there was no statistically significant difference between the resin restorations placed in bulk and those placed in three increments. ${ }^{42}$

Studies about Sonic and Bulk-fill reported low contraction stress, increase marginal integrity, reduce bulk fracture and no voids..$^{43}$ The effect of lowering viscosity and conversion from multiple layering to bulked single layer of composite to increase adaptation of the composite and to improve ease of placement has been shown to be important. ${ }^{44}$ There were no significant differences between groups 2 and 3, and this came in agreement with Tayel et al. that reported slightly better marginal seal for sonically adapted composite resin than the other restorative techniques used. ${ }^{45}$

\section{CONCLUSIONS}

Within the limitations of this study, the obtained results of the present study could be concluded that the restorative techniques used with bulkfill or sonic-fill composites does not change the microleakage potential which is comparable to that of incrementally placed composite. Also, Sonic-fill composite showed less microleakage than the other conventional and Bulk-fill composites.

\section{REFERENCES}

1. Gaengler P, Hoyer I, Montag R. Clinical evaluation of posterior composite restorations: the 10-year report. J Dentistry 2001; 3:185-94.

2. Ernst C-P, Kotter T, Victor A, Canbek K, Brandenbusch M, Willershausen B. Marginal integrity of self-and totaletching adhesives in two different application protocols. $\mathrm{J}$ Dent 2004; 6:25-32.

3. Braga RR, Ferracane JL. Alternatives in polymerization contraction stress management. Critical Reviews in Oral Biol \& Med 2004; 15:176-84.

4. Garcia D, Yaman P, Dennison J, Neiva G. Polymerization shrinkage and depth of cure of bulk fill flowable composite resins. Oper Dent 2014; 39:441-8.

5. Opdam N, Feilzer A, Roeters J, Smale I. Class I occlusal composite resin restorations: in vivo post-operative sensitivity, wall adaptation, and microleakage. Am J Dent 1998; 11:229-34. 
6. Kwon Y, Ferracane J, Lee I-B. Effect of layering methods, composite type, and flowable liner on the polymerization shrinkage stress of light cured composites. Dent Mater 2012; 28:801-9.

7. Czasch P, Ilie N. In vitro comparison of mechanical properties and degree of cure of bulk fill composites. Clin Oral Investig 2013; 17:227-35.

8. Ahmad I. Deep resins, white fillings: A new technique for composite restorations. J Cosmet Dent 2013; 3:22-31.

9. Iovan G, Stoleriu S, Moldovanu A, Morogai S, Andrian S. SEM study of the interface between the cavity wall and composite resin in cavities filled using vibration. Int J Med Dent 2011; 1:254-8.

10. Giachetti L.A new method for direct composite restoration of the posterior teeth. J Dental Tribune Middle East and African edition - 2014

11. Benetti AR, Havndrup-Petersen C, Honore D, Pedersen MK, Pallesen U. Bulk-fill resin composites: Polymerization contraction, depth of cure, and gap formation. Oper Dent 2015;40: 190-200.

12. Roulet J, Reich T, Blunck U, Noack M. Quantitative margin analysis in the scanning electron microscope. Scanning microscopy $1989 ; 3: 147-58$.

13. Colak H, Ercan E, Hamidi MM. Shear bond strength of bulk-fill and nano-restorative materials to dentin. Eur J Dent 2016; 10:40-5.

14. Dietschi D, Monasevic M, Krejci I, Davidson C. Marginal and internal adaptation of class II restorations after immediate or delayed composite placement. J Dent 2002; 30:259-69.

15. Scotti N, Comba A, Gambino A, Paolino DS, Alovisi M, Pasqualini D, Berutti E. Microleakage at enamel and dentin margins with a bulk fills flowable resin. Eur J Dent 2014; 8:1-8.

16. Moorthy A, Fleming GJ, Hogg CH, Dowling AH, Grufferty BF, Benetti AR. Cuspal deflection and microleakage in premolar teeth restored with bulk- fill flowable resin -based composite materials basis. J Dent 2012; 40:500-5.

17. Cobanoglu N, Kara E, Unlu N, Ozer F. Bacterial microleakage of aged adhesive restorations. European $\mathrm{J}$ Gen Dent 2015; 4:3-7.

18. Cramer N, Stansbury J, Bowman C. Recent advances and developments in composite dental restorative materials. $\mathrm{J}$ Dent Res 2011; 90:402-16.
19. Browne RM, Tobias RS. Microbial microleakage and pulpal inflammation: a review. Dent Traumatol 1986; 2:177-83.

20. Singh M, Palekar A. Polymerization shrinkage of composite resins: A review. NJDSR 2014; 1:2:58-61.

21. Kato G, Nakabayashi N. The durability of adhesion to phosphoric acid etched, wet dentin substrates. Dent Mater J 1998; 14:347-52.

22. Kubo J, Yokota H, Sata Y, Hayashi Y. The effect of flexural load cycling on the microleakage of cervical resin composites. Oper Dent J 2001; 26:451-9.

23. Gupta KV, Verma P, Trivedi A. Evaluation of microleakage of various restorative materials: An in vitro study. J life Sci 2011; 3:29-33.

24. Dietschi D, U. Scampa, G. Campanile and J. Holz. Marginal adaptation and seal of direct and indirect Class II composite resin restorations: an in vitro evaluation. Quintessence Int 1995; 26: 127-38.

25. Ilie N, Stark K. Curing behavior of high-viscosity bulk-fill composites. J Dent 2014; 42: 977-985.

26. Abdalla A, Davidson C. Comparison of the marginal integrity of in vivo and in vitro Class II composite restorations. J Dent 1993; 21:158-62.

27. Deliperi S, Bardwell DN, Wegley C. Restoration interface microleakage using one total-etch and three self-etch adhesives. Oper Dent. 2007; 32:179-84.

28. Kidd Edwina AM. Microleakage: A review. J Dent 1976; 4:199-206.

29. Yamazaki PC, Bedran-Russo AK, Pereira PN, Wsift EJ Jr. Microleakage evaluation of a new low-shrinkage composite restorative material. Oper Dent. 2006; 31:6706.

30. Alani AH, Toh CG. Detection of microleakage around dental restorations: A review. Oper Dent 1997;22:173-85

31. Wahab FK, Shaini FJ, Morgano SM. The effect of thermocycling on microleakage of several commercially available composite Class V restorations in vitro. J Prosthet Dent 2003; 90:168-74.

32. Schmalz G, Ergücü Z, Hiller KA. Eff ect of dentin on the antibacterial activity of dentin bonding agents. J Endod 2004; 30:352-8.

33. Ernest Rose E, Joginder L, Williams N, Falcettil J.The 
screening of materials for adhesion to human tooth structure. J Dent Res 1995; 34: 577-88.

34. Eunice C MA, Joao C L, Filomena B, Anabela P, Pedro A, Marques F. M. $99 \mathrm{~m}$ Tc in the evaluation of microleakage of composite resin restorations with Sonic An in vitro experimental model. Open J Stomatol 2012; 2: 340-7.

35. Poggio C, Chiesa M, Scribante A, Mekler J, Colombo M. Microleakage in Class II composite restorations with margins below the CEJ: In vitro evaluation of different restorative techniques. Med Oral Patol Oral Cir Bucal. 2013; 18: 793-8.

36. Loguercio AD, Reis A, Schroeder M, Balducci I, Versluis A, Ballester RY. Polymerization shrinkage: effects of boundary conditions and filling technique of resin composite restorations. J Dent 2004; 32:459-70.

37. Hassan M, Ghulam M. Effect of ultrasonic packing on interfacial adaptation of a densely filled resin composite in high C-factor cavities. Egypt Dent J 2006; 52:1-7.

38. Schmidlin PR, Wolleb K, Imfeld T, Gygax M, Lussi A. Influence of beveling and ultrasound application on marginal adaptation of box-only Class II (slot) resin composite restorations. Oper Dent 2007; 32:291-297.

39. Orłowski M, Tarczydło B, Chałas R. Evaluation of marginal integrity of four bulk-fill dental composite materials: in vitro study. The Scientific World Journal 2015; 2015:1-8.

40. Rizzante FAP, Mondelli RFL, Furuse AY, Borges AFS, Mendonça G, Ishikiriama SK. Shrinkage stress and elastic modulus assessment of bulk-fill composites. J Appl Oral Sci. 2019; 27: 1-9.

41. Singh S, Rajkumar B, Gupta V, Bahatt A. Current photoinitiators in dental materials. Inter J Appl Dent Sci 2017; 3: $17-20$.

42. Behery H, El-Mowafy O, El-Badrawy W, Nabih S, Saleh B. Gingival microleakage of class II bulk-fill composite resin restorations. Dent \& Med Probl 2018; 55:383-8.

43. Frankenberger R. Marginal quality and associated cusp displacement of SonicFill restorations. Kerr Corp Fill Portf SciRes; 2012; p. 2.

44. Clelland NL, Pagnotto MP, Kerby RE, Seghi RR. Relative wear of flowable and highly filled composite. J Prosthet Dent 2005; 93:153-7.

45. Tayel D, El-Sharkawy M, Mahmoud M. Microleakage of Class II Composite Restorations with Different Restorative Techniques (An In Vitro Study). Alexandria Dent J 2016; 41:138-145. 